\title{
ENTRE EL MEDITERRÁNEO Y EL SENO MEXICANO: EL INGENIERO MILITAR ANTONIO DONCEL
}

\section{BETWEEN THE MEDITERRANEAN SEA AND THE MEXICAN SINE: THE MILITARY ENGINEER ANTONIO DONCEL}

\author{
Miguel Ángel Nieto Márquez ${ }^{1}$ \\ Universidad de Sevilla
}

\section{RESUMEN}

En el siglo XVIII, gran parte de los ingenieros militares que eran destinados a América habían llevado a cabo trabajos previos en el ámbito Mediterráneo. Uno de ellos fue Antonio Doncel y Adel, un profesional poco conocido que fue destinado a Nueva España en 1763 para servir al virrey marqués de Cruillas en las obras de la plaza de Veracruz. No obstante, a pesar de dicho desconocimiento, su trayectoria se produjo en puntos geográficos de relevancia, intuyéndose por la documentación conservada una importante valoración de su trabajo por parte de sus superiores. El presente artículo pone de relieve la figura de este ingeniero, aportando nuevas noticias sobre su vida profesional y personal, y profundizando sobre sus trabajos y ocupaciones tras regresar de su destino americano, destacando su segunda etapa en Cádiz y su papel como ingeniero director en el reino de Granada.

Palabras clave: fortificaciones, revellín, cuartel, Josef Spalletti, Cabo de Gata

\begin{abstract}
In the 18th century, many military engineers who were assigned to America had previously worked in the Mediterranean area. One of them was Antonio Doncel y Adel, a little-known professional who was posted to New Spain in 1763 to serve the viceroy Marquis de Cruillas in the construction of the Plaza de Veracruz. However, despite this lack of knowledge, his career took place in geographic points of relevance, intuiting from the preserved documentation an important assessment of his work by his superiors. This article highlights the figure of this engineer, providing news about his professional and personal life, and delving into his jobs and occupations after returning from his American destination, highlighting his second stage in Cádiz and his role as director engineer in the kingdom of Granada.
\end{abstract}

Key words: fortifications, ravelin, barracks, Josef Spalletti, Cabo de Gata

1 El presente artículo se inscribe en el desarrollo del proyecto de investigación I+D "PGC2018-099323-B-I00. Arquitecturas del poder en el Caribe y el Sudeste Asiático. 1729-1764”, financiado por el Ministerio de Ciencia, Innovación y Universidades. 


\section{INTRODUCCIÓN}

En la segunda mitad del siglo XVIII, el virreinato de Nueva España mantenía la importancia estratégica que adquirió en el quinientos. Por ello, la defensa de la plaza de Veracruz y del castillo de San Juan de Ulúa se convirtió en una prioridad para los sucesivos virreyes, debido a su condición de "llave de Nueva España". No obstante, también fue fundamental el cuidado de otras plazas del Golfo de México, como las de la provincia de Yucatán y de la Florida. Estas labores de fortificación fueron encomendadas a los ingenieros militares, quienes desde la creación del Real Cuerpo de Ingenieros en 1711 recibieron su formación e instrucción para ello, encargándose también de reconocimientos territoriales, labores cartográficas y de obras públicas (Gutiérrez, 2005: 31-34 y 73).

La mayoría de los ingenieros que trabajaron en el seno mexicano en esta época también desarrollaron su carrera en el Mediterráneo, destacando su participación en las campañas italianas, su labor en los presidios africanos y sus destinos en las costas mediterráneas peninsulares, sin olvidar la presencia de algunos de ellos en las islas Baleares. Agustín López de la Cámara Alta, Lorenzo de Solís, Manuel de Santisteban, Miguel Constanzó o Miguel del Corral fueron algunos de los profesionales que desarrollaron su carrera en ambos ámbitos, si bien existen otros menos conocidos, como es el caso de Antonio Doncel, a quien se dedica el presente estudio.

Hasta el momento, la historiografía ha estudiado la labor de este ingeniero de una forma parcial y fragmentada. No obstante, la importancia de sus destinos y proyectos unida a la buena opinión que de él tenían sus superiores, son pruebas de una relevancia que aún no se ha destacado lo suficiente. Por tanto, se pretende ahora poner en valor la figura de este ingeniero, sentándose las bases para nuevos estudios que vengan a aclarar las incógnitas que persisten sobre su carrera profesional.

\section{EL REAL CUERPO DE INGENIEROS EN TIEMPOS DE ANTONIO DONCEL}

La creación del Real Cuerpo de Ingenieros, fruto de las ideas francesas llegadas de mano de Felipe V, supuso un mayor protagonismo del papel de los ingenieros militares españoles. Desde el descubrimiento del nuevo continente, los extensos dominios de la Corona hispana requirieron la presencia de un buen número de estos profesionales, quienes se encargaron de elaborar sistemas defensivos para su protección, sin olvidar otras tareas como los reconocimientos territoriales, la elaboración de mapas o la proyección de obras públicas (Cantera, 2003: 25). No obstante, la presencia de dichos profesionales en tierras americanas fue limitada, hasta que se produjo la creación del citado Cuerpo y avanzó el siglo XVIII.

La carrera del ingeniero militar Antonio Doncel se desarrolló en un momento en el que se estaban efectuando importantes movimientos en dicha institución. De hecho, en 1761 se produjo su incorporación a la Secretaría de Guerra, de modo que los ingenieros se desvincularon del cuerpo de artilleros. Dos años después, Maximiliano de la Croix fue nombrado Comandante General del Cuerpo de Ingenieros e Inspector General de las plazas y fortificaciones del Reino, iniciando una serie de reformas entre las que destacó el aumento de la plantilla, que llegó a alcanzar los 150 ingenieros. Estaban distribuidos de la siguiente forma: 10 ingenieros directores, 10 ingenieros en jefe, 20 ingenieros en segundo, 30 ordinarios, 40 extraordinarios y 40 delineadores (Capel, 1988: 64-66).

Con su llegada al mando del Cuerpo en 1766, Juan Martín Cermeño propuso ampliar el número de efectivos y fundar un ramo especializado en puentes, caminos y canales. Aunque estas propuestas fueron denegadas por las ordenanzas de 1768, en 1774, ya fallecido Martín Cermeño, sí se llevó a cabo una división del Cuerpo en tres áreas: el Ramo de Plazas y Fortificaciones del Reino, el Ramo de Academias Militares y el Ramo de Caminos, Puentes, Edificios de Arquitectura Civil y Canales de riego y navegación, que fueron dirigidos por Silvestre Abarca, Pedro Lucuce y Francisco Sabatini, respectivamente (Carrillo de Albornoz, 2012: 92).

Sin embargo, volviendo a las ordenanzas de 1768, que fueron publicadas en un solo tomo compuesto de tres partes, se definió el régimen y el servicio de los ingenieros, se aclararon las distintas formas de planteamiento y ejecución de fortificaciones y se detallaron los diversos servicios que los ingenieros debían desarrollar en campañas militares. En ellas también se aportaron nuevas ideas relativas a las competencias de estos profesionales, otorgándose más 
poder a los ingenieros directores respecto a las funciones y a los destinos de sus subordinados. Por otra parte, también se produjo un intento por limitar las labores de los ingenieros en obras de carácter civil para así enfocar sus esfuerzos en los trabajos de fortificación, si bien se siguieron encargando de este tipo de edificios durante buena parte del siglo siguiente (Cruz, 2017: 62).

\section{EL INGENIERO MILITAR ANTONIO DONCEL. PRIMEROS AÑOS}

Nacido en Arres de Jos, en el Valle de Arán (Lérida) hacia 1732, se conoce que Antonio Doncel y Adel comenzó a servir en el ejército a muy temprana edad, el 6 de mayo de 1746. Al año siguiente, tras ingresar como cadete en el Regimiento de Infantería de Granada, participó en la campaña de Niza, y tras pasar por el Regimiento Saboya y ser repatriado ese mismo año, ingresó en el Regimiento de la Reina, estudiando posteriormente en la Academia de Matemáticas de Barcelona. Sus estudios se extendieron hasta el año 1755, momento en que fue destinado a Cádiz tras recibir el 21 de octubre el grado de subteniente de infantería y el empleo de ayudante de ingeniero. Cinco años más tarde, el 25 de marzo de 1760, se tiene constancia de su casamiento, ya que, en una carta firmada en Madrid, Maximiliano de la Croix manifiesta haber recibido la certificación de matrimonio. Más tarde, el 22 de julio, Doncel ascendió a teniente y a ingeniero extraordinario, firmando dos meses después un plano de la plaza de Cádiz ${ }^{2}$ (Cano, 1994: 174)

Dicho documento, datado el 12 de septiembre de 1760 con el visto bueno de Silvestre Abarca, recoge proyectos de fortificaciones, cuarteles y edificios reales. Sin embargo, en el título de este plano aparece el año 1735, un dato que la historiografía aún no ha clarificado si se debe a un error o si Doncel quiso hacer referencia a otro dibujo del que se pudo servir (Calderón, 1978: 150-152). En cualquier caso, en el plano aparece representado un arrecife que había sido destruido por el mar y un nuevo camino cuyas obras estaban recién iniciadas (Cano, 1993: 46), mientras que el camino viejo se encuentra más al borde de la playa, prácticamente enterrado por las arenas. Por otra parte, en el lugar conocido como Camposanto y junto al Hospital Real, correspondiente a la zona comprendida actualmente entre la plaza del Mentidero y el Gran Teatro Falla, aparecen dos cuarteles proyectados, mientras que otros dos se localizan en terrenos de la Alameda. También se puede comprobar que el Hospicio u Hospital de Santa Elena se estaba construyendo, y que la Torre de San Sebastián estaba siendo utilizada como almacén de pólvora después de que el ingeniero Pedro Borrás la hubiera adaptado en 1727. Por lo demás, cabe destacar la amplia explicación numerada donde se especifican los distintos edificios y fortificaciones de la ciudad (Calderón, 1978: 150-152), entre las que destacan la batería de las Peñuelas, la del Romano, la de la Aguada o el castillo del Puntal (Ruiz, 2016: 320).

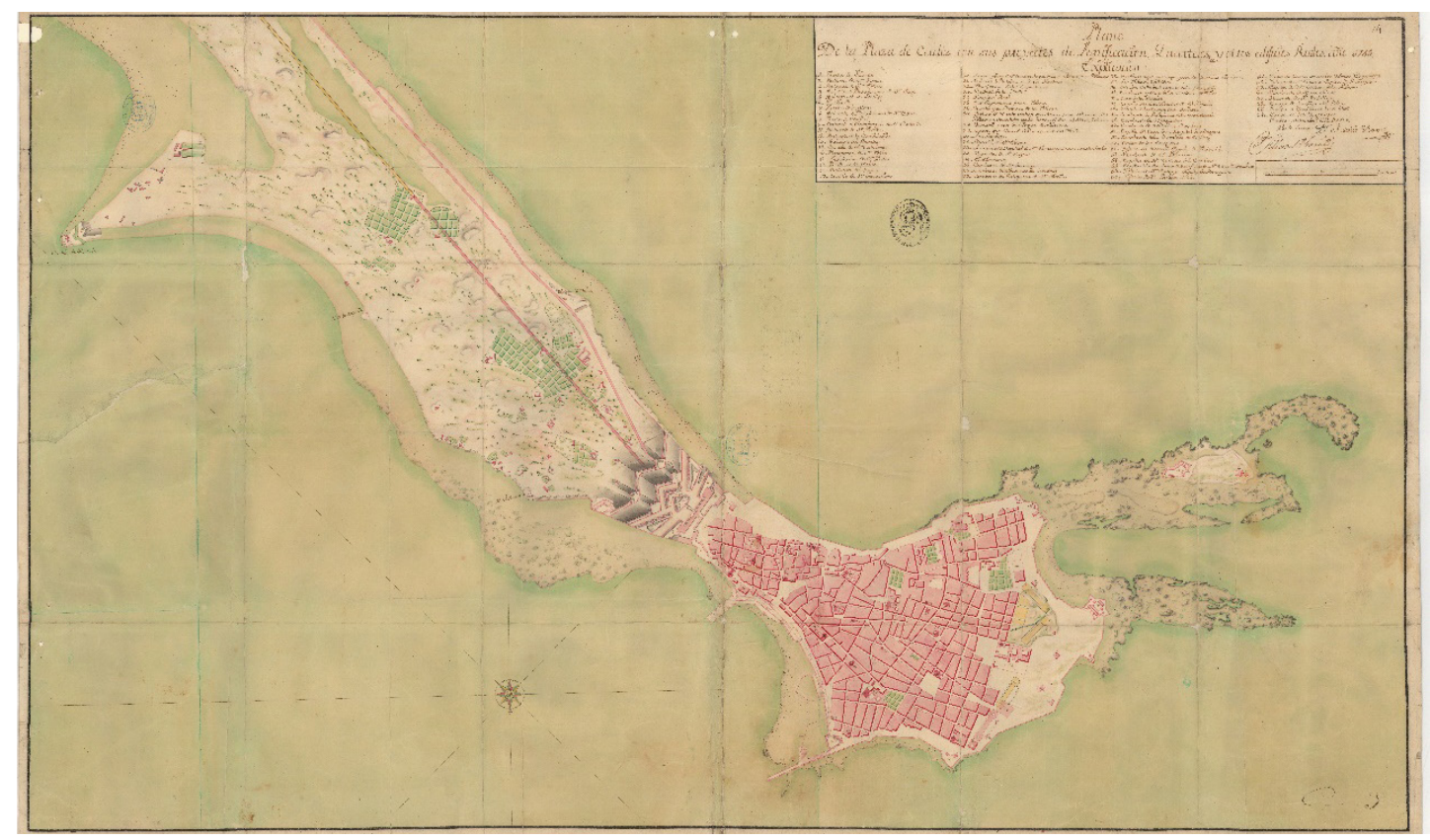

Figura 1. Antonio Doncel. Planta de Cádiz. 1760.

2 Plano de Cádiz en 12 de septiembre de 1760. España. Ministerio de Defensa, Archivo General Militar de Madrid (AGMM) CA-30/01. 


\section{DESTINO A NUEVA ESPAÑA}

Durante el siglo XVIII, llegaron al virreinato de Nueva España 95 ingenieros, siempre escalonadamente. A mediados de dicho siglo, se establecieron normas para el destino de estos profesionales al continente americano, de modo que ascenderían a un empleo superior una vez incorporados, aunque debían permanecer en el nuevo destino al menos cinco años (Laorden 2008: 20). Antonio Doncel fue destinado a Nueva España para servir al virrey marqués de Cruillas en 1763, llevando a cabo dicho traslado siendo ingeniero extraordinario y teniente, si bien ya había solicitado su ascenso a capitán (Cano, 1994: 175). Antes de su marcha, el 12 de abril, el marqués del Real Tesoro le envió al Secretario de Estado de Marina y de Indias, Julián de Arriaga, el memorial en el que Doncel solicitaba licencia para embarcarse. A partir de esta documentación, conservada en el Archivo General de Indias, ha podido descubrirse que la mujer con la que estuvo casado se llamaba Raimunda, con quien había tenido un hijo. Asimismo, en dicho documento el ingeniero hacía constar que con su sueldo no podía mantener a su familia (esposa, hermana e hijo) ni a sus dos criados, a la vez que alegaba sus 17 años de servicio al rey (9 como cadete de infantería y 8 en el Cuerpo de Ingenieros), asegurando haber cumplido con su deber de forma satisfactoria y destacando su labor en la Guerra de Italia ${ }^{3}$. Por todo ello, solicitaba su ascenso a capitán estando aún en Cádiz (Capel 1983: 154).

El 22 de abril, el ingeniero ya había conseguido su destino a México, a donde le acompañaron su hijo y sus dos criados. Sin embargo, Raimunda Doncel tuvo que permanecer en España a causa de una enfermedad que le impedía embarcar, por lo que, siendo inminente el viaje, el ingeniero solicitó una ayuda económica de 20 pesos anuales para su alimentación, una cantidad que le fue concedida a partir del 1 de mayo, descontándosela de su sueldo en el nuevo destino ${ }^{4}$. Con estos datos, Antonio Doncel pasa a ser uno de los ingenieros militares casados que fueron destinados a los territorios americanos, cuando lo habitual era que se destinaran solteros.

Tras estos trámites, Doncel embarcó hacia Nueva España en la expedición del conde de Ricla (Gómez, 2000), produciéndose su llegada a Veracruz el 19 de agosto a bordo del navío El Buen Consejo, capitaneado por Joaquín de Olivares. Poco tiempo antes, el virrey marqués de Cruillas había solicitado el envío de seis ingenieros para la continuación de las obras de aquella plaza, ya que en ese momento solo contaba con Agustín López de la Cámara Alta y Pedro Ponce. Por esta razón, junto a Doncel llegaron los ingenieros Manuel de Santisteban y Miguel Ximénez. No obstante, la escasez de ingenieros no se solventó, ya que Ximénez falleció al poco tiempo de desembarcar, mientras que Cámara Alta murió antes de que los nuevos profesionales citados llegaran al virreinato (Calderón 1984: 156). En el mes de diciembre, el mencionado marqués del Real Tesoro se volvió a dirigir a Julián de Arriaga para que permitiera embarcar a Raimunda Doncel a Nueva España, que ya se había recuperado de sus dolencias y estaba dispuesta a reunirse con el resto de su familia. El permiso le fue concedido ${ }^{6}$.

\section{LABORES DE ANTONIO DONCEL EN VERACRUZ}

Durante los cinco años que Doncel estuvo destinado en la plaza de Veracruz, trabajó como ingeniero extraordinario a las órdenes de Manuel de Santisteban, tanto en la ciudad como en la cimentación del revellín de la Gallega del castillo de San Juan de Ulúa (1765), donde continuaba empleado en $1766^{7}$.

Dichas labores fueron llevadas a cabo en un tiempo en que la defensa y la fortificación de la costa veracruzana estaba sin resolver. El general Juan de Villalba, destinado por el rey a Nueva España para organizar en el virreinato un cuerpo de tropas regulares, consideraba

3 El marqués del Real Tesoro a Julián de Arriaga. 12 de abril de 1763. Archivo General de Indias (AGI). MÉXICO, 2450.

4 Al virrey marqués de Cruillas. 30 de abril de 1763. AGI. MÉXICO, 2450.

5 Al virrey de Nueva España. Madrid, 21 de julio de 1767. AGI. MÉXICO, 2455. El virrey marqués de Cruillas a Julián de Arriaga. 18 de agosto de 1763. AGI. MÉXICO, 2450.

6 El marqués del Real Tesoro a Julián de Arriaga. Cádiz, 13 de diciembre de 1763. AGI. MÉXICO, 2450. Al marqués del Real Tesoro. Madrid, 6 de diciembre de 1763. AGI. MÉXICO, 2450. Raimunda Doncel. Cádiz, 22 de noviembre de 1763. AGI. MÉXICO, 2450.

7 Manuel de Santisteban a Félix de Ferraz. Veracruz, 8 de junio de 1766. AGI. MÉXICO, 2453 
que lo único útil sería la construcción de una ciudadela con capacidad para mil hombres, aunque no contemplaba tomar ninguna decisión, ya que, a pesar de que su opinión coincidía con la de los ingenieros militares, dichas defensas eran consideradas por el conde de Aranda ociosas y perjudiciales. En este contexto, entre marzo y agosto de 1765, el mariscal Antonio Ricardos y su equipo de ingenieros realizaron un reconocimiento de las costas norte y sur de Veracruz, resultando de ello un importante trabajo topográfico y un complejo proyecto de defensa. Con este material y la asistencia del visitador general José de Gálvez, se celebraron ante el virrey cuatro Juntas de Guerra entre septiembre y octubre, resolviéndose en la primera de ellas la ejecución de una serie de medidas de fortificación que habían sido estudiadas por Santisteban, Miguel del Corral y el mismo Ricardos para la fortaleza de Ulúa. Consistían en la modificación del baluarte de San José, en la parte de la Gallega (Antolín, 1967: 122-123).

El proyecto de revellín fue realizado por Santisteban de mayor tamaño que la batería y el baluarte de San José, que al estar en ruinas le sirvieron de origen. De planta hexagonal, se proyectó con seis bóvedas a prueba de bomba y otra capital un poco más amplia. Se conservan dos planos de este proyecto, uno firmado el 26 de febrero de 1765 y otro el 3 de abril, contando el segundo con una forma más aguda, conforme al primer informe de Santisteban. Además, en los espacios terraplenados de los frentes que flanquean la bóveda capital, se puede comprobar cómo en el primer proyecto hay solo dos contrafuertes interiores, mientras que en el segundo hay tres, favoreciendo el mayor tamaño y ángulo del vértice del revellín en el primero. Este quedaría completamente aislado, rodeado de foso y protegido por un camino cubierto, plaza de armas, traveses y explanada, añadiéndosele a las baterías bajas dos medios baluartes para el flanqueo y la defensa de los frentes y protegiéndose con estacadas los trozos de cortina que no estaban defendidos. Por último, se proyectó un aumento de la cortina de la fortaleza que miraba a la Gallega para colocar la artillería, para así articular sus fuegos con el proyectado revellín. El presupuesto, aprobado por el rey, ascendió a 183.709 pesos, 5 reales y 2 tercios sin contar los sueldos y los jornales (Calderón 1984: 162)

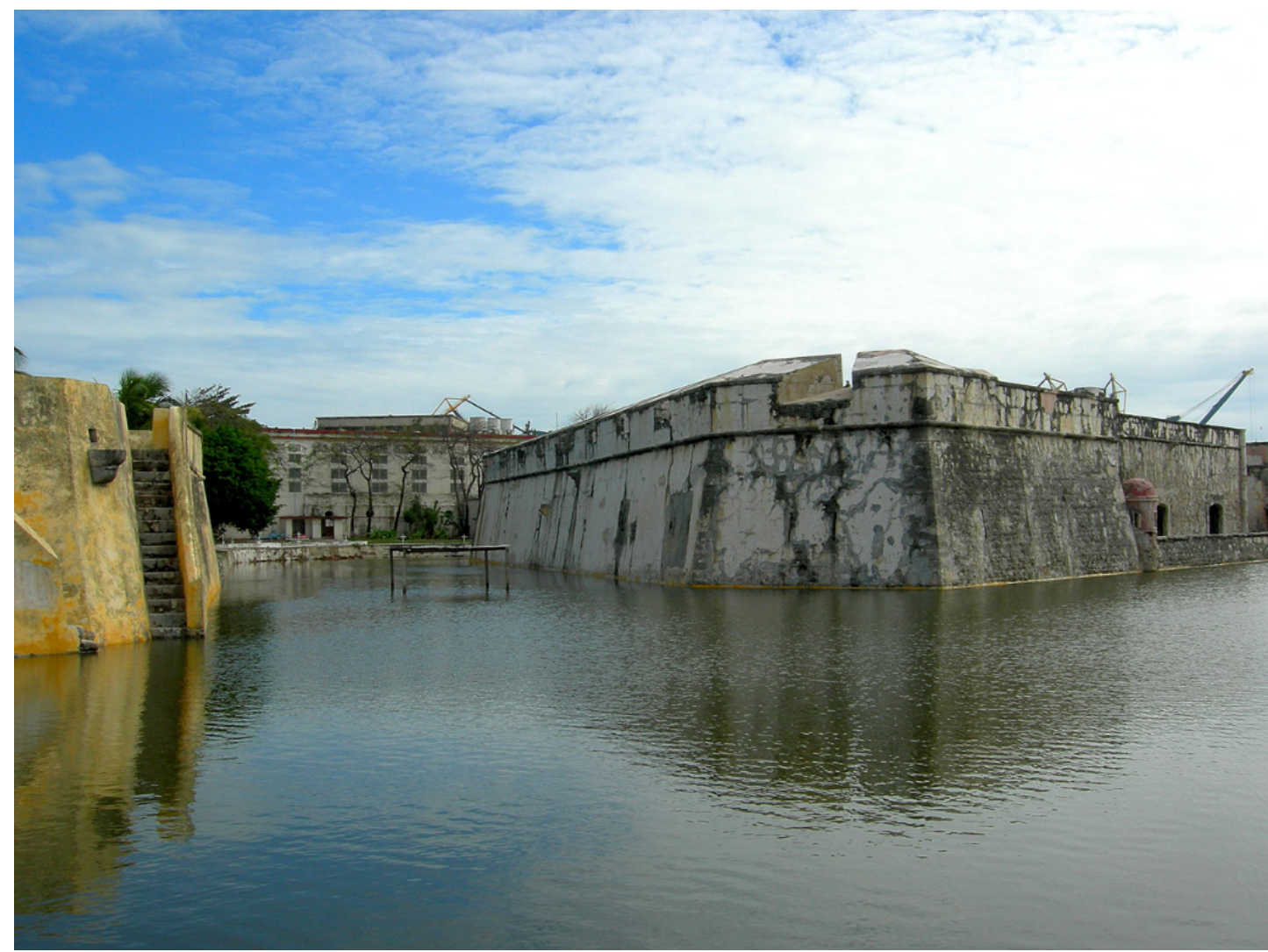

Figura 2. Estado actual del revellín del frente de la Gallega. Castillo de San Juan de Ulúa, Veracruz. Fotografía de Alfredo J. Morales

8 Los planos de este proyecto fueron publicados en dicha obra de José Antonio Calderón Quijano (figs. 48 y 49). 
El 5 de febrero de 1766, Manuel de Santisteban da constancia del comienzo de las obras de cimentación del nuevo revellín, así como se conoce que en julio ya se había concluido prácticamente la ampliación de la muralla con sus bóvedas (Antolín, 1967: 124). El papel de Antonio Doncel en estos trabajos y en los de la plaza veracruzana sigue estando por precisar, si bien su conducta debió ser intachable, siendo prueba de ello el apoyo que le prestó el virrey marqués de Croix en 1767 en su solicitud para ascender a capitán y volver a España (Capel, 1983: 154). Dicho regreso se produjo por los problemas de salud que había ocasionado al ingeniero el clima veracruzano, de modo que su esposa Raimunda, que aún no había embarcado hacia Nueva España, solicitó que su marido pudiera regresar a la Península. El permiso fue aprobado por el rey el 4 de abril de 1767, mientras que el 28 de mayo del año siguiente, Antonio Doncel comunicó a Julián de Arriaga su llegada a España9 .

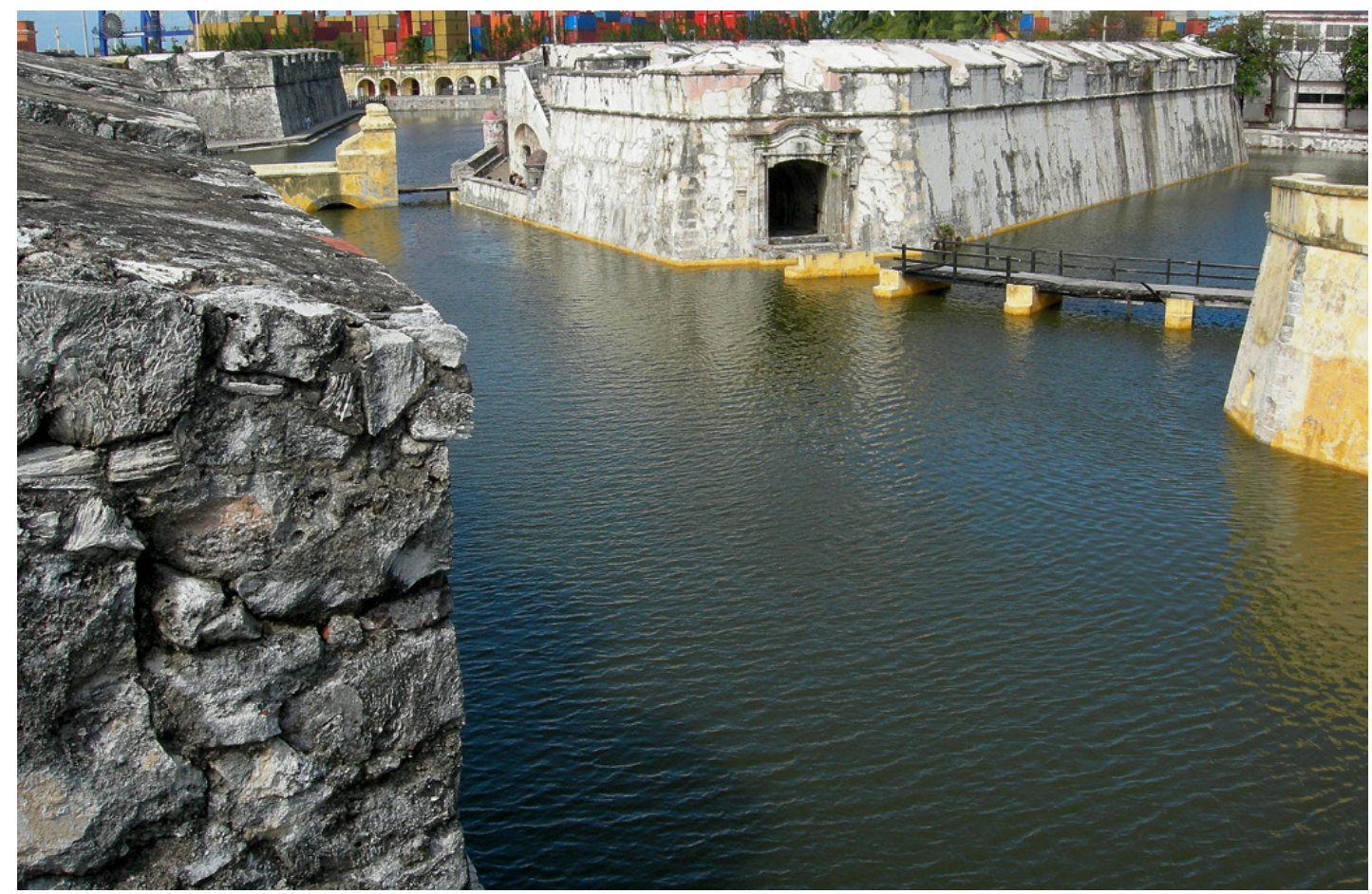

Figura 3. Estado actual del revellín del frente de la Gallega. Castillo de San Juan de Ulúa, Veracruz.

Fotografía de Alfredo J. Morales

\section{SEGUNDA ETAPA EN CÁDIZ}

Una vez en la Península, fue destinado nuevamente a Cádiz, donde definitivamente consiguió su ascenso a capitán e ingeniero ordinario en 1770 (Cano, 1994: 175). De esta nueva etapa gaditana, se localiza en el Archivo General de Simancas un plano fechado en 1771 de un cuartel de caballería para Algeciras, un edificio que se había proyectado en 1755 y comenzado a construir al año siguiente. No obstante, al poco tiempo las obras quedaron paralizadas, por lo que Doncel realizó este plano representando en encarnado lo que ya se había construido y en amarillo lo que faltaba por levantar. El plano acompañaba a una carta firmada el 22 de febrero de 1771 por el comandante general del Campo de Gibraltar, Joaquín de Mendoza Pacheco, dirigida a Juan Gregorio Muniain, secretario de Estado y del Despacho de Guerra, incluyéndose a la vez una instancia de Francisco Dacarrete donde se solicitaba la conclusión del cuartel y un cálculo de la obra ${ }^{10}$. En 1783, se conoce que las obras ya habían comenzado (Ponce y Sánchez, 2004: 45).

9 A D. Gregorio Muniain. Palacio, 25 de junio de 1768. AGI. MÉXICO, 2455. Instancia de Raimunda Doncel. Madrid, 28 de marzo de 1767. AGI. MÉXICO, 2455. Al virrey marqués de Croix. Madrid, 4 de abril de 1767. AGI. MÉXICO, 2455. Relación realizada por Manuel de Santisteban de los ingenieros destinados en Nueva España. Veracruz, 6 de marzo de 1768. AGI. MÉXICO, 2455. Antonio Doncel a Julián de Arriaga. Madrid, 28 de mayo de 1768. AGI. MÉXICO, 2455.

10 España. Ministerio de Cultura. Archivo General de Simancas (AGS). Material cartográfico, MPD, 18, 235. AGS. Secretaría de Guerra, Legajos, 03265. 
Como se indica en el título del plano, este cuartel estaba destinado a acoger a 135 caballos, no habiéndose terminado la primera cuadra. Según el documento, de esta cuadra se llegaron a cubrir 19 metros de largo, colocándose las vigas del piso hasta la mitad, con sus paredes colaterales y la pared de división de 3 metros de alto. El plano representa el perfil y la planta rectangular del edificio, y cuenta con dos pequeñas solapas para distinguir el piso inferior del superior. Bajo el título, en clave alfabética, aparece la explicación del plano, y tanto debajo del perfil como de la planta están detalladas las escalas, de 16 y 33 metros respectivamente.

Así, se puede comprobar que el cuartel está dispuesto en torno a un patio (N), y que contaba con dos entradas principales (A), una para acceder directamente a las cuadras y otra para el resto de las estancias. Al patio central se ingresaba por otras dos puertas (B) que, además, como se indica en el mismo plano, servían para comunicar ambas cuadras, enlazadas en su extremo con las escaleras de subida al piso superior (C y R). Respecto a las cuadras, muy alargadas, se observa cómo aparecen distribuidas a ambos lados con sus pesebres $(\mathrm{H})$, dividiéndose el espacio por medio de pilares y arcos, contando además con un pequeño espacio para el repuesto de paja junto a una de las puertas del patio (L).

Las estancias de la izquierda y de la derecha, que son las que aparecen representadas en el perfil, son las habituales en un edificio de este tipo. En la planta baja se distribuyen el cuarto del oficial de piquete (D), el cuerpo de guardia (E), una habitación que podía servir de calabozo (F) y una cocina para la tropa (G). Por su parte, en el piso superior se encontraban las viviendas, en concreto la de los sargentos $(\mathrm{O})$ y la del oficial $(\mathrm{P})$, y un lugar común dividido por un tabique para evitar la comunicación de una cuadra con otra (S). En cuanto al patio, en el centro hay un pozo y una pila para abrevar los caballos (Q), y también se representa una cañería para el desagüe del lugar común (M). Finalmente, con la letra I se representa un muro antiguo que estaba elevado hasta el primer piso.

Por tanto, se comprueba cómo este proyecto responde a las necesidades que tenían los cuarteles en aquel momento. Naturalmente, al tener que dar acomodo y alojamiento a los caballos, esta tipología de cuartel debía contar con una mayor superficie que los de infantería, lo que conllevaba poca disponibilidad de espacio para los jinetes (Cantera, 2007: 51 y 61). Por otra parte, se advierten influencias del modelo de cuartel propuesto por Bertrand Fores de Belidor

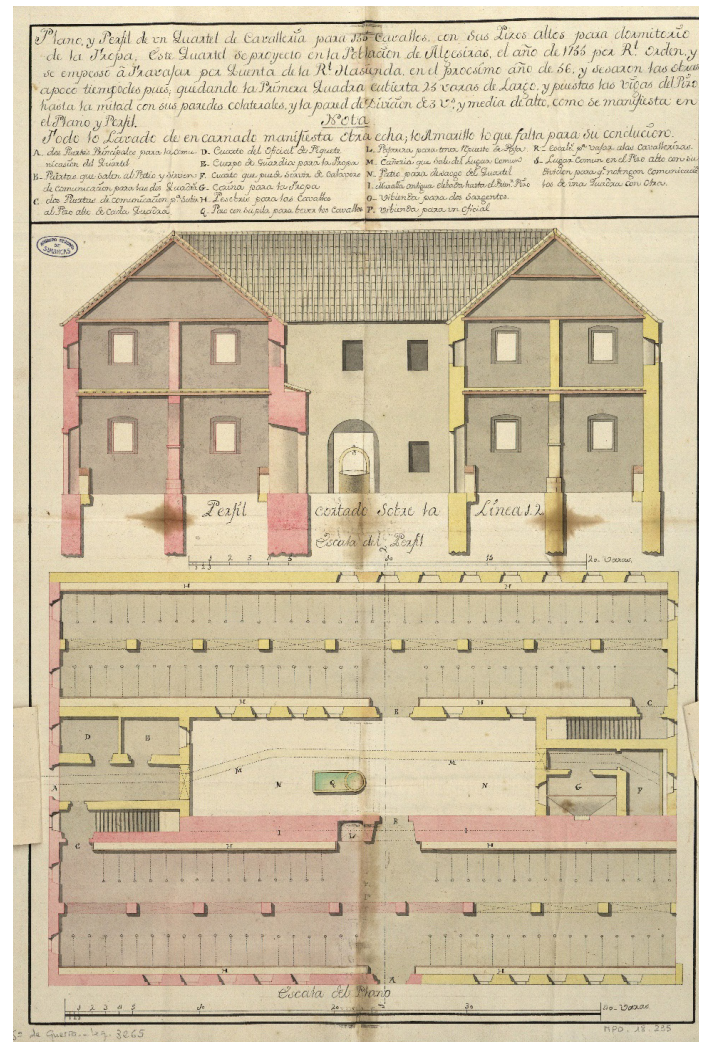

Figura 4. Antonio Doncel. Plano y perfil para un cuartel de caballería en Algeciras. 1771 (Planta baja)

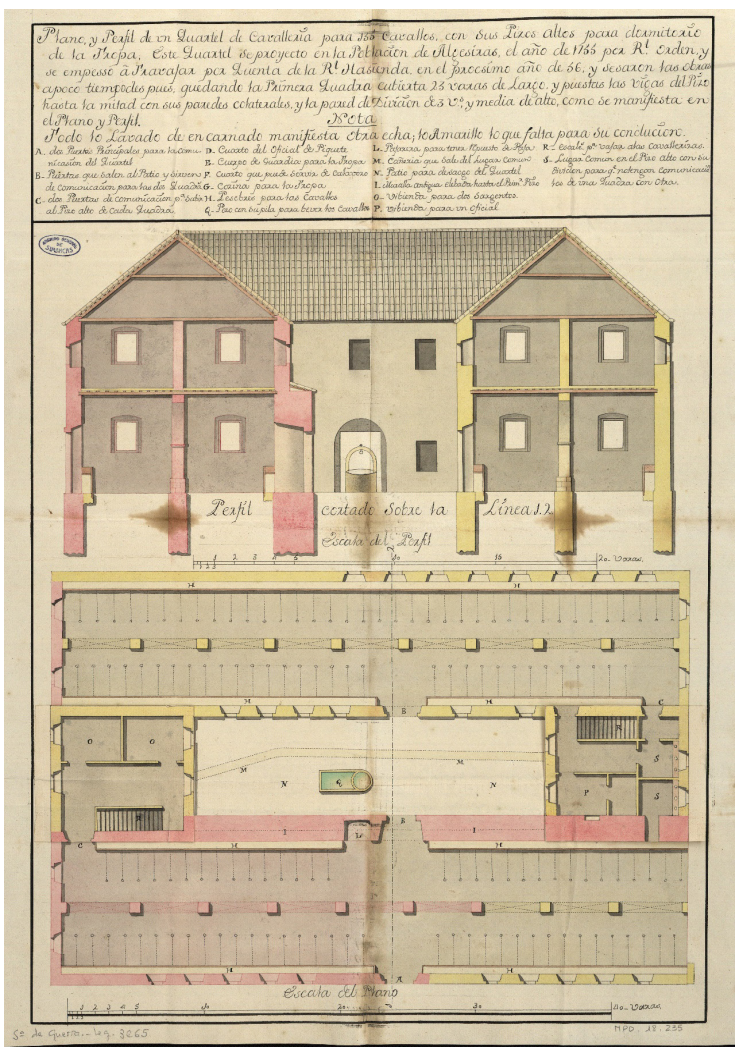

Figura 5. Antonio Doncel. Plano para un cuartel de caballería en Algeciras. 1771 (Planta alta) 
en su obra La Science de l'Ingenieur dans la conduite des travaux de Fortification et d'Architecture, que fue publicada en 1729, consistente en cuatro bloques alargados dispuestos formando un patio cuadrado en el centro, mejorando así el modelo de Vauban (Cantera, 2007: 53). Se consigue así que el cuartel pasara a formar parte de la ciudad, sin la necesidad de construirse cerca o adosados a las edificaciones fortificadas, como ocurría con el modelo de Vauban (Marzal, 1978: 4 y Hernández, 1991: 241). Esta tipología era muy propicia para un cuartel de caballería, ya que el patio sería el lugar propicio para poder ejercitarse con los caballos (Cantera, 2007: 53). En este caso concreto, como ya se ha comentado, el patio posibilitaba la comunicación entre ambas cuadras, así como contaba con una pila para que los animales abrevaran.

Esta tipología de cuartel puede relacionarse con otros proyectos contemporáneos debidos a otros ingenieros militares. Por ejemplo, cabe destacar la adaptación que en 1764 Manuel de Santisteban realizó del proyecto de Lorenzo Rodríguez para el cuartel de caballería para el palacio virreinal de México, donde nuevamente un patio central con pila se encuentra rodeado por las cuadras, al igual que ocurre con las propuestas de 1761 de Agustín López de la Cámara Alta y Pedro Ponce para el mismo fin (Angulo, 1939: 384-386). De igual modo, también puede relacionarse con el proyecto de Lorenzo de Solís y Cámara Alta para el cuartel de infantería del regimiento de la Corona, en Veracruz, que también responde a las ideas anteriormente comentadas respecto a la construcción de acuartelamientos (Nieto, 2021).

Aún en Cádiz, Doncel solicitó en 1778 su ascenso a ingeniero en segundo (Capel, 1983: 154), y hacia 1779 realizó un plano de las inmediaciones de Gibraltar (Gil, 2004: 96). Concretamente, del 31 de julio de 1779 es un croquis conservado en el Archivo Histórico Nacional de dos caminos que unen la población de Los Barrios con la Venta del Arrecife en Cádiz, pasando uno por Vejer y Chiclana y otro por Casas Viejas y Medina Sidonia. En este documento, Doncel recogió los puentes, alcantarillas y calzadas que era necesario construir, así como se refiere a la apertura de carriles y a algunos reparos (Capel, 1983: 154 y León, 1969: 32). Por otro lado, en opinión de Gil Albarracín, con anterioridad a 1779 debió realizar el plano sin fechar de parte de la fortificación de la plaza de Almería, así como el del fuerte de San José, en la costa del Cabo de Gata, una zona donde más adelante desempeñaría otro cometido (Gil, 2006: 96 y Capel: 1983: 154).

\section{CONTIENDAS EN MENORCA Y GIBRALTAR. OBRAS EN MELILLA}

Cabe destacar también el papel de Antonio Doncel en ciertos conflictos bélicos. En junio de 1781 participó como ingeniero en la expedición del duque de Crillón para recuperar Menorca del dominio inglés. Gracias a los trabajos realizados en esta operación franco-española, finalizada con éxito el 5 de febrero de 1782 (Terrón, 1998), el ingeniero consiguió su ascenso a teniente coronel e ingeniero en segundo el 2 de diciembre ${ }^{11}$, si bien sus labores allí son aún una incógnita. En el mismo año de 1782, también participó con el duque de Crillón en el asedio y fallido sitio de Gibraltar (1779-1783), siendo al año siguiente promovido a coronel, concretamente el 1 de enero (Cano, 1994: 175).

Por esta época, Gil Albarracín señala que probablemente regresó a América, ya que existe constancia de un informe sobre este ingeniero redactado en 1785 por el ingeniero director Manuel Santisteban (Gil, 2004: 96). Sin embargo, no se ha podido confirmar ese posible regreso, pero sí que el 25 de octubre de 1790 se convirtió en ingeniero en jefe ${ }^{12}$ (Cano, 1994: 175). Tras dicho ascenso, su nombre está presente en los expedientes de una serie de obras proyectadas en Melilla por el ingeniero José Ampudia y Valdés, concretamente del muelle, de la Maestranza, de la Batería de San Felipe y de toda la plaza, apareciendo su visto bueno como ingeniero en jefe en un plano de las fortificaciones de Melilla firmado el 11 de julio de 1792. Toda esta documentación ha sido localizada también en el Archivo General de Simancas ${ }^{13}$.

\footnotetext{
11 Véase: Noticias de España. Madrid. En Mercurio histórico y político, diciembre de 1781, 380.

12 Véase: Noticias de España, Madrid. En Mercurio histórico y político, noviembre de 1790, 612

13 España. Ministerio de Cultura. AGS. Material cartográfico, MPD, 65, 011; MPD, 65, 006; MPD, 65, 013; 65, 014. ; MPD, 65, 015.
} 


\section{ANTONIO DONCEL EN LA COSTA DEL REINO DE GRANADA}

El 20 de diciembre de 1794, Antonio Doncel se convirtió en el ingeniero director de las obras de la costa de Granada, si bien su residencia la estableció en Málaga (Cano, 1994: 175-176). Desde este momento, de acuerdo a las atribuciones de su cargo, Doncel se encargaría de supervisar las obras del reino granadino, delegando su realización en el resto de ingenieros. Igualmente, entraban en sus competencias la elaboración de los presupuestos de los trabajos, la administración de la distribución de los ingenieros en su provincia, su evaluación e incluso su sanción o arresto (Galland, 2005: 219).

De esta etapa, también se han localizado en el Archivo General de Simancas dos planos en los que aparece su visto bueno, si bien están firmados por Josef Spalletti, un ingeniero militar muy desconocido. El primero de ellos corresponde al antiguo castillo de Rodalquilar, firmado el 18 de mayo de 1797, que acompañó a una carta remitida como ingeniero director de Málaga a Francisco Sabatini el 21 de junio ${ }^{14}$. El otro plano recibió su visto bueno el 8 de diciembre, consistiendo en un dibujo de una torre-atalaya de Motril que se había proyectado para sustituir a la Torre del Chucho tras haber quedado inutilizada. Este documento incluye además una relación donde se manifiestan las obras, reparos y disposiciones más urgentes para 1798, acompañada del cálculo del importe de su construcción ${ }^{15}$.

El antiguo castillo de Rodalquilar, también conocido como Torre de los Alumbres, era una fortaleza renacentista que fue construida a raíz del descubrimiento de un importante yacimiento de Alumbre en 1509 en el corredor que une el valle con el Playazo de Rodalquilar. Levantado para proteger la explotación minera, diversos documentos dejan constancia de la necesidad que existía de artillarla y restaurarla en el siglo XVIII, destacando los informes de ingenieros como Felipe Crame (1733), Jerónimo Amici (1749) o Agustín de Ibáñez (1752) (Gil, 2004: 430-433). El deseo de mejorar esta fortificación no debe resultar extraño, ya que su planta es un claro precedente de lo que serían los cuadrados abaluartados, que fueron las estructuras más exitosas en la defensa del Caribe durante el siglo XVIII (Cruz, 2020: 9-10).

Sin embargo, el progresivo abandono de esta fortificación no se puede entender sin referirse a Antonio María Bucareli y Ursúa, que antes de marchar a América para convertirse

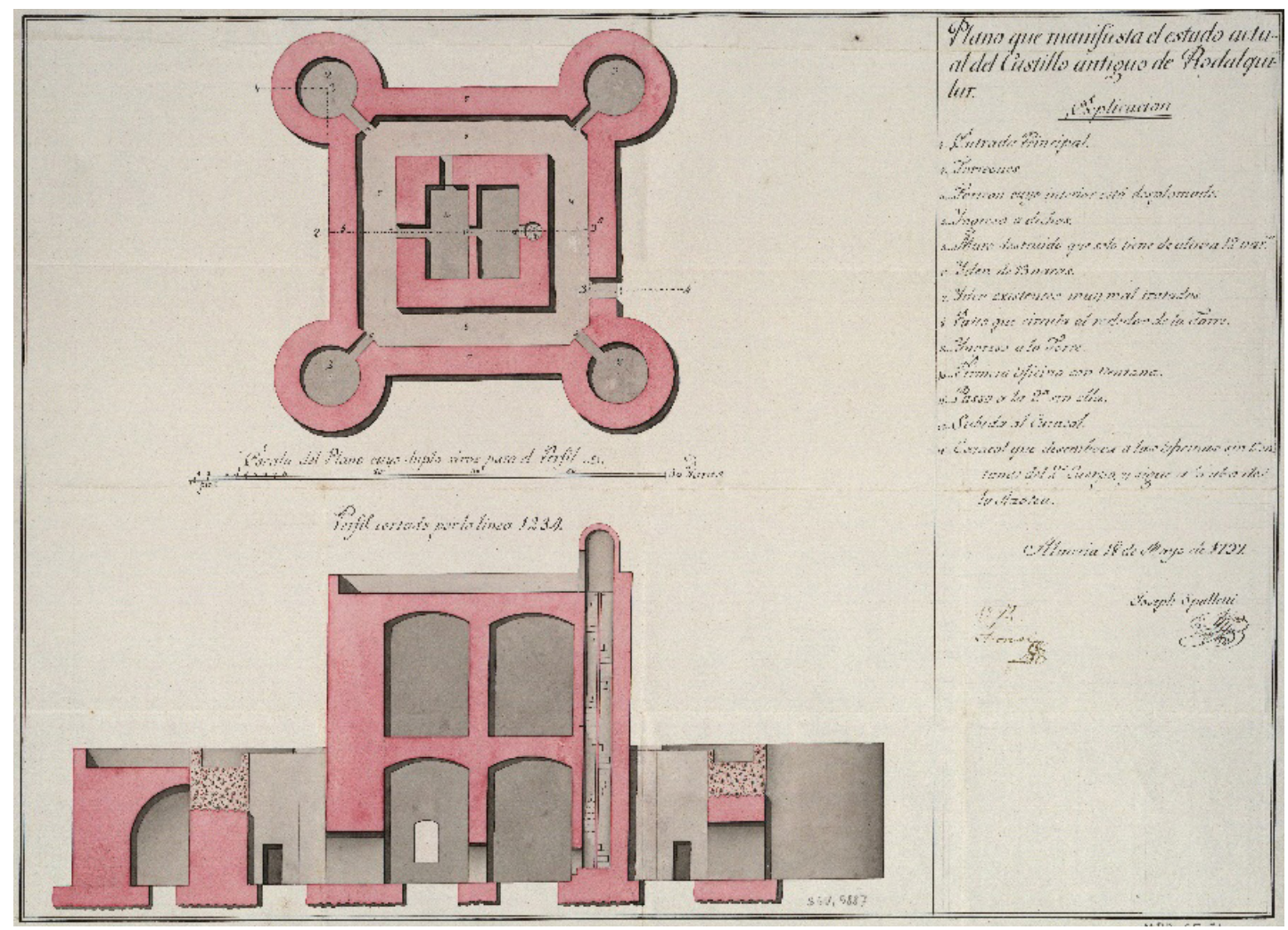

Figura 6. Josef Spalletti. Plano del antiguo Castillo de Rodalquilar. 1797

14 España. Ministerio de Cultura. AGS. Material cartográfico, MPD, 65, 074; Secretaría de Guerra, Legajos, 05887.

15 España. Ministerio de CUltura. AGS. Material cartográfico, MPD, 65, 073; Secretaría de Guerra, Legajos, 05887. 
en virrey de Nueva España, recibió en 1761 la orden de reconocer las fortificaciones de la costa del reino de Granada, así como de redactar un informe con las propuestas para solucionar de forma definitiva la defensa de dicho litoral. En este documento, que sirvió de inspiración para el reglamento promulgado en Madrid el 18 de agosto de 1764, se decidió la construcción de la batería de Rodalquilar y de la torre del Cerro de los Lobos (Gil, 1995: 54).

Respecto a la torre fuerte, única fortificación existente en aquel paraje entonces, el informe de Bucareli supuso prácticamente la liquidación de su función defensiva, aunque su inmediatez a la playa le permitió seguir siendo aprovechada para situar en ella la guarnición necesaria para vigilar ese tramo de litoral. Bucareli propuso la construcción de una torre con dos cañones en un emplazamiento más idóneo, sustituyendo a la Torre de los Alumbres desde el punto de vista defensivo. Según Gil Albarracín, una vez levantada la nueva fortificación de Rodalquilar, la antigua casa fuerte quedó sin valor militar y desapareció de los informes, aunque su presencia siguió llamando la atención de quienes pasaban por sus inmediaciones (Gil, 1995: 81-82). No obstante, la existencia del plano de Spalletti con el visto bueno de Doncel, demuestra que esta vieja fortificación sí seguía en los informes y acaparaba la atención de la ingeniería militar a finales del siglo XVIII.

La defensa de las costas del reino de Granada fue una preocupación de la Corona desde tiempos de Felipe II, cuando ya se le ordenó al ingeniero Juan de Oviedo y de la Bandera una serie de torres atalayas dotadas de artillería y separadas por una cierta distancia, comunicándose unas con otras a través de lienzos blancos o por fuegos durante la noche. Eran cuadradas o cilíndricas, de 12 y 15 metros de altura por 5 y 8 metros de diámetro, y muy similares entre sí: terraplenadas en su tercio inferior, con una o dos bóvedas en su interior y sin escaleras para hacerlas más inaccesibles (Pérez, 1977: 69-70).

El plano de la torre-atalaya de Motril, como se indica en el mismo encabezamiento, es una copia del mismo Josef Spalletti del realizado para el Proyecto General de las ocho atalayas que se debían construir en la costa de Granada en el año 1765, firmado por José Crame en Málaga el 25 de octubre y autorizado por el marqués de Esquilache en Madrid el 8 de diciembre del mismo año (Gil, 2004: 62-63; 1996: 95-97). De esta forma, aparece representada en forma de cono truncado, debiéndose construir en mampostería excepto el cordón, coronamiento, fogaril y marcos de puertas y ventanas, que serían de sillería. En el interior albergaría dos cámaras, estando abovedada la superior. Su coste se estimó en 13.420 reales de vellón por unidad, si bien se redondeaba a 15.000 de cara a los imprevistos que pudieran surgir. La misma estructura muestran la Torre García, la de la Testa, las de la Vela Blanca y de Cala Higuera, pudiéndose nombrar otras como la Torre de Piedras Rodadas, la Torre de los Genoveses, la Torre de Monsul o el Sabinar (Gil, 1996: 99-125).

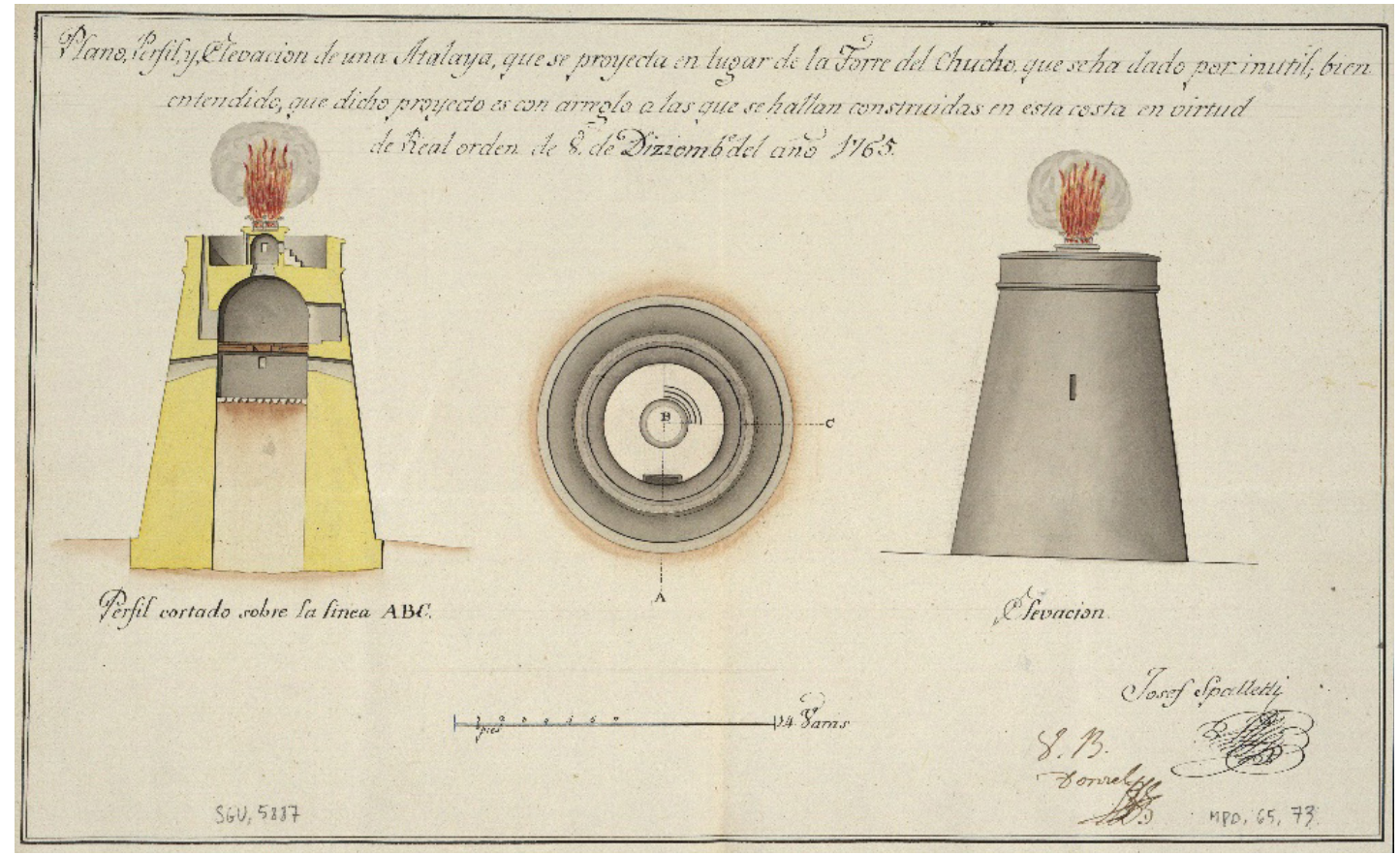

Figura 7. Josef Spalletti. Proyecto para la desaparecida Torre del Chucho. 1797 
Como se señalaba con anterioridad, esta torre-atalaya vendría a sustituir a la Torre del Chucho, situada en el cerro del mismo nombre y que en 1797 estaba inutilizada. Dicho estado ya había quedado reflejado en un informe realizado en Málaga el 12 de diciembre de 1781 por Francisco Gozar, quien ya manifestó la necesidad de construir otra de nueva planta en una mejor situación, suponiendo un coste de 25.000 reales de vellón una vez lo aprobara el monarca. Sin embargo, el rey nunca aceptó ninguna propuesta para su construcción, por lo que desde entonces hasta la segunda mitad del siglo XIX la torre continuó arruinándose (Gil, 2004: 484-485). Por tanto, la propuesta de 1797 también quedó sobre el papel, aunque es un elemento que contribuye al conocimiento de la carrera profesional de Doncel en este destino.

Los últimos años de la carrera de Antonio Doncel, al igual que toda su carrera profesional, no están claros. Parece ser que con posterioridad a sus trabajos en el reino de Granada fue destinado como ingeniero director a Extremadura, siendo la última noticia de este ingeniero su presencia en el Campo de San Roque, en Cádiz (Cano, 1994: 176). Al no figurar en el Cuerpo de Ingenieros en el año 1805, se ha supuesto que por entonces ya debería haber fallecido.

\section{CONCLUSIONES}

En definitiva, Antonio Doncel es uno de los ingenieros que, a pesar de haber desarrollado su carrera en puntos geográficos de relevancia, continúa necesitado de estudio. Como se ha podido comprobar a lo largo de este texto, su carrera no está bien conocida, existiendo muchas lagunas entre sus destinos, aunque ello no oculta su importancia. Además, las publicaciones y la documentación de archivo utilizada para el presente trabajo reflejan que debió ser un profesional muy valorado, ya que no se han hallado datos que lo sitúen en alguna situación conflictiva con otros ingenieros o con autoridades.

Cabe destacar también sus circunstancias familiares, habiéndose documentado en este estudio la identidad de su esposa, Raimunda Doncel, así como la presencia de su hijo y de sus dos criados en Veracruz cuando el ingeniero fue destinado a Nueva España. Asimismo, llaman la atención las facilidades de su mujer para conseguir ayudas económicas, así como para conseguir el permiso para su viaje frustrado a Veracruz a causa del repentino regreso de su marido a España, también solicitado por ella.

Aunque de su segunda etapa en Cádiz y de su destino en el reino de Granada existen datos, sigue desconociéndose gran parte del final de su vida, ignorándose incluso el año de su fallecimiento. Por este motivo, el presente artículo pretende poner de relieve la figura de este ingeniero, que merece ser investigada para continuar completando el amplio campo de estudio de los ingenieros militares al servicio de la Corona española. 


\section{BIBLIOGRAFÍA}

- Angulo Íñiguez, D. (1939). Planos de monumentos arquitectónicos de América y Filipinas existentes en el Archivo de Indias. Estudio de los planos y su documentación I. Sevilla: Laboratorio de Arte.

- Antolín Espino, M. P. (1967). El Virrey Marqués de Cruillas (1760-1766). En Calderón Quijano, J. A. (Dir.). Los virreyes de Nueva España en el reinado de Carlos III. Tomo I. Sevilla: Escuela de Estudios Hispanoamericanos. Consejo Superior de Investigaciones Científicas. Url: http://hdl.handle.net/10261/35493

- Calderón Quijano, J. A. (1984). Historia de las fortificaciones en Nueva España. Sevilla: Consejo Superior de Investigaciones Científicas.

- Calderón Quijano, J. A; Fernández Cano, V; Sarabia Viejo, M. J. (1978). Cartografía militar y marítima de Cádiz. Sevilla: Escuela de Estudios Hispanoamericanos.

- Cano Révora, M. a G. (1994). Cádiz y el Real Cuerpo de Ingenieros Militares (1697-1847). Utilidad y firmeza. Cádiz: Universidad de Cádiz.

- Cano Révora, M. ${ }^{a}$ G; Torrejón Chaves, J. (1993). La ciudad de Cádiz y su acceso terrestre: aspectos financieros de la obra del arrecife (1759-1792). Cuadernos de Ilustración y Romanticismo, 1 (3), 43-55.

- Cantera Montenegro, J. (2007). La "Domus Militaris" hispana. Origen, evolución y función social del cuartel en España. Madrid: Ministerio de Defensa.

- Cantera Montenegro, J. (2003). Arquitectos e ingenieros: los ingenieros militares en el adelantamiento de la España ilustrada. En De la Paz de París a Trafalgar. La organización de la defensa de la monarquía. Madrid: Ministerio de Defensa. Instituto Español de Estudios Estratégicos, 24-82.

- Capel, H; Sánchez, J. E; Moncada, O. (1988). De Palas a Minerva. La formación científica y la estructura institucional de los ingenieros militares en el siglo XVIII. Barcelona, Serbal.

- Capel, H. y otros. (1983). Los ingenieros militares en España, siglo XVIII: Repertorio biográfico e inventario de su labor cientifica y espacial. Barcelona: Universidad de Barcelona. Url: http:// hdl.handle.net/2445/67042

- Carrillo de Albornoz y Galbeño, J. La edad de oro de la fortificación abaluartada en España y Ultramar. Revista de Historia Militar, N. . Extra 1, 33-98.

- Cruz Freire, P. y otros. (2020). Estrategia y propaganda. Arquitectura militar en el Caribe (1689-1748). Roma-Bristol: "L’Erma" di Bretschneider.

- Cruz Freire, P. (2017). Silvestre Abarca. Un ingeniero militar al servicio de la monarquía hispana. Sevilla: Athenaica.

- Galland Seguela, M. (2005). Los ingenieros militares españoles en el siglo XVIII. En Cámara, A. (Coord.). Los ingenieros militares de la monarquía hispánica en los siglos XVII y XVIII. Madrid: Ministerio de Defensa. Asociación Española de Amigos de los Castillos. Centro de Estudios Europa Hispánica.

- Gil Albarracín, A. (2004). Documentos sobre la defensa de la costa del Reino de Granada (14971857). Barcelona: Ingoprint.

- Gil Albarracín, A. (1996). Atalayas y fortalezas en el Parque Natural de Cabo de Gata-Níjar (arquitectura e historia). Almería-Barcelona: GBG Editora.

- Gil Albarracín, A. (1995): Los castillos de Rodalquilar en el Parque Natural de Cabo de GataNijar (arquitectura e historia). Almería-Barcelona: GBG Editora.

- Gómez Pellejero, J. V. (2000). Nobleza militar y redes del poder en el siglo XVIII: El VIII Conde de Ricla. Revista Zurita, 75, 107-131.

- Gutiérrez, R. (2005). Fortificaciones en Iberoamérica. Madrid: Ediciones el Viso.

- Hernández Núñez, J. C. (1991). Gerónimo Amici y los proyectos de cuarteles para el regimiento de caballería de Andalucía, en la provincia de Huelva. Espacio, Tiempo y Forma, Serie VII, Historia del Arte, t. 4, 239-264. Url: https://hdl.handle.net/11441/69854

- Laorden Ramos, C. (2008). Obra civil en Ultramar del Real Cuerpo de Ingenieros I. Virreinatos de Nueva España y Nueva Granada. Madrid: Ministerio de Defensa. Colegio de Ingenieros de Caminos, Canales y Puertos.

- León Tello, P. (1969). Mapas, planos y dibujos de la sección de Estado del Archivo Histórico Nacional. Madrid: Dirección General de Archivos y Bibliotecas.

- Marzal Martínez, A. (1978). Notas sobre arquitectura militar dieciochesca en Andalucía. 
Cuarteles. I Congreso de Historia de Andalucía. Andalucía Moderna (siglo XVIII), tomo II, 3-20.

- Nieto Márquez, M. A. (2021). El ingeniero Lorenzo de Solís y los cuarteles de la plaza de Veracruz. En Identidades y redes culturales. V Congreso Internacional de Barroco Iberoamericano. Granada: Universidad de Granada, pp. 843-850.

- Pérez Escolano, V (1977). Juan de Oviedo y de la Bandera (1565-1625). Escultor, arquitecto e ingeniero. Sevilla: Publicaciones de la Excma. Diputación Provincial de Sevilla.

- Ponce Ortiz de Insagurbe, M; Sánchez Sánchez, J. (2004): Sevilla: arquitectura y ciudad militar. El Cuartel de la Carne, patrimonio recuperado. Sevilla: Diputación de Sevilla.

- Ruiz Nieto-Guerrero, María Pilar; Jiménez Mata, Juan José (2016): Historia urbana de Cádiz. I. Génesis y formación de una ciudad moderna. Cádiz: Colegio Oficial de Arquitectos de Cádiz.

- Terrón Ponce, J. L. (1998). La toma de Menorca (1781-1782) en los escritos autobiográficos y epistolario del duque de Crillon. Menorca: Institut Menorquí d’Estudis. Fundació Rubió Tudurí Andrómaco. 